\begin{tabular}{|c|c|}
\hline \multirow{3}{*}{ 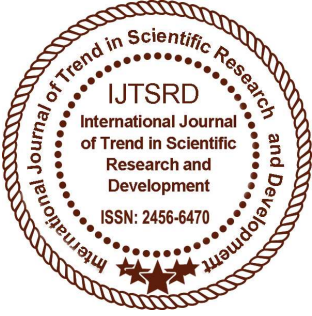 } & $\begin{array}{l}\text { International Journal of Trend in Scientific } \\
\text { Research and Development (IJTSRD) }\end{array}$ \\
\hline & International Open Access Journal \\
\hline & ISSN No: 2456 - 6470 | www.ijtsrd.com | Volume - 2 | Issue - 4 \\
\hline
\end{tabular}

\title{
Study and Optimization of Car Hood for Pedestrian Head Safety by Using Simulation Technique
}

\author{
Mukesh C. Chaudhari, Tushar D. Kumbhani \\ Assistant Professor, Mechanical Engineering Department, Vadodara Institute of Engineering, \\ Vadodara, Gujarat, India
}

\begin{abstract}
Head and face injuries in pedestrian- car accidents account for $60 \%$ of all pedestrian fatal injuries, whereas $17.3 \%$ of head injuries were due to the car hood. The above ratios show the necessity to consider carefully the role of the hood in pedestrian head safety. Redesigning the hood structure to improve pedestrian protection has recently received considerable attention by automobile manufacturers and industry institutes. However, there is a lack of research that considers methods of choosing the most effective thicknesses of hood skin and hood reinforcement with respect to pedestrian safety.

The aim of these tests was to compare the general pedestrian friendliness of steel and aluminum, used as hood material. The tests were conducted on a car that is still available on the market with either a steel or aluminum hood, both having the same design.
\end{abstract}

Keywords: hood, head injury, Pedestrian safety

\section{INTRODUCTION}

The hood and bumper, with which pedestrians come in frequent contact, can be designed and manufactured to be pedestrian friendly, effectively decreasing injuries [3]. During the development of a safe hood and bumper structures, experiments and computer simulations are used to evaluate their performances Computer simulations contain many errors from inaccurate modeling and approximation of governing Equations. On the other hand, experiments are considered to be accurate even with the possibility of experimental errors and inaccuracies. In design, it would be the best if all the data could be obtained from experiments. However, an experiment is generally very costly. Therefore, limited experiments are performed in many application fields. In this case, some experiments can be replaced by computer simulations. As mentioned earlier, computer simulation has a large amount of errors [3].

To compare the pedestrian fatal accident numbers of different countries, Table 1 take account of the respective population size. The numbers of pedestrian fatalities are 6359 from 26 countries of EU country. The maximum number of pedestrian fatalities is from Polska is about 1408 in year 2011.

In India Delhi city accounted for $25.1 \%$ deaths of bicycle riders, $18.8 \%$ deaths of pedestrians, $16.6 \%$ deaths of two-wheeler riders and $9.2 \%$ deaths of 3 wheeler riders in 35 metro cities. [4] Fig. 1 shows that the pedestrian death in year 2010 is about $9.1 \%$.

Number of Pedestrian Deaths

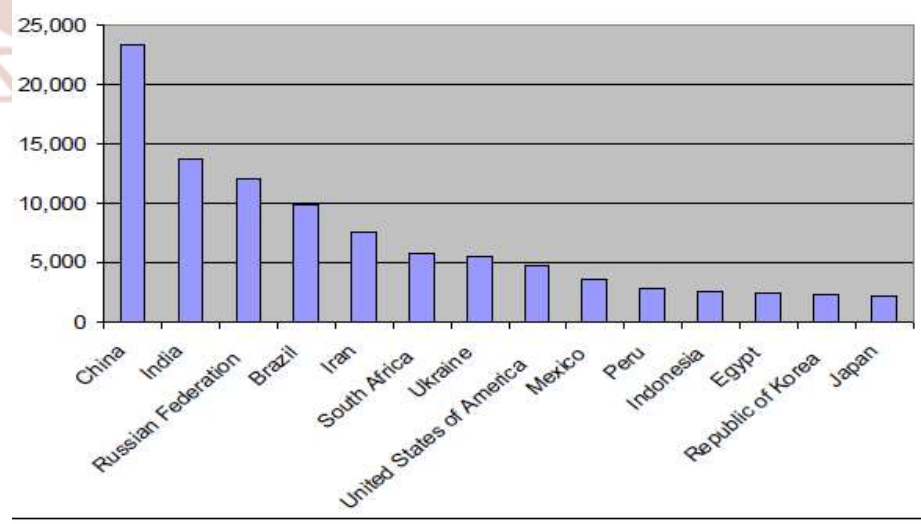

Figure 1 Number of Pedestrian Deaths by Country [1] 
As expected, more crowded countries will have higher total numbers of pedestrian deaths with China, India, and the Russian Federation in first, second, and third in that category, respectively.

\section{Experimental set up}

Figure 2 shows the experimental set up for the test of hood. The angle for adult pedestrian is taken as $65^{\circ}$ when it is falling on hood and the wrap around distance is $1700-2100 \mathrm{~mm}$. The wrap around distance is the distance measured from ground surface to the hood surface when the head will be impacted when the height of pedestrian is $154 \mathrm{~cm}$. For child pedestrian the wrap around distance is taken as $1000-1700 \mathrm{~mm}$ depending on the height of the pedestrian.

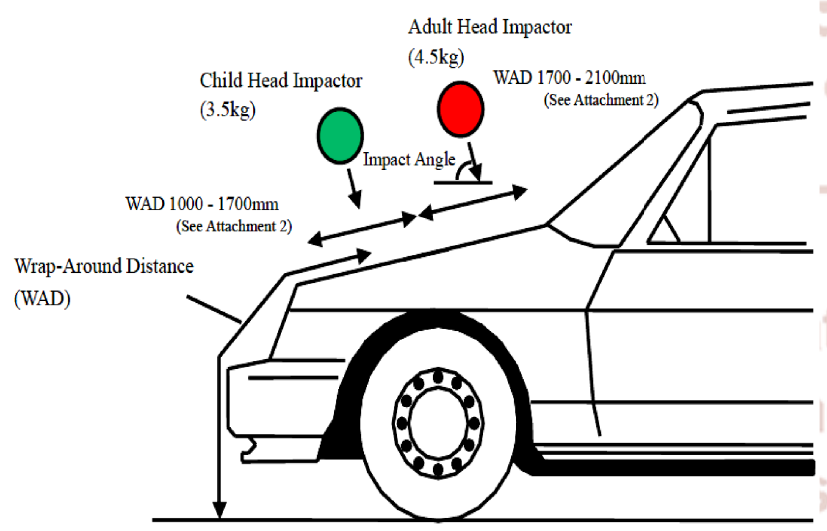

Figure 2 Pedestrian protection concept proposed by the EEVC WG17 [5]

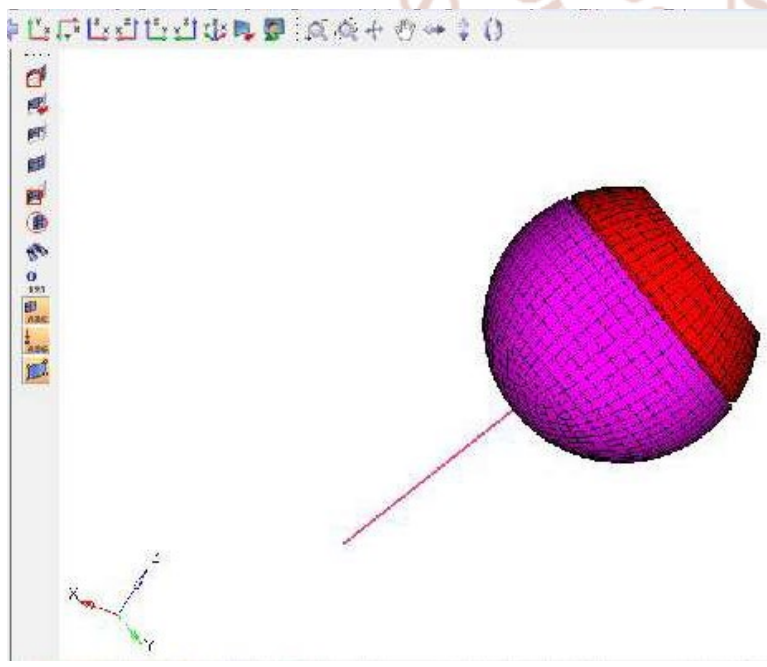

Fig. 2 Head model with $4 \mathrm{~kg}$ selected

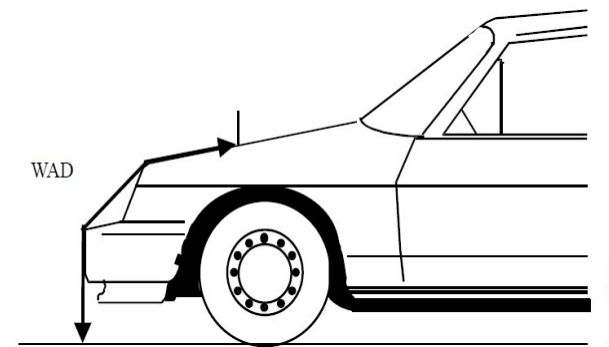

Figure 4 Determination of WAD [5]

The wrap around distance is measured by using string.

\section{Reduced Fe Model Preparation}

The full co related model of Toyota Yaris is reduced by cutting it from the B-Pillar and removing the front wheels, seats, door etc. The model is reduced such that the test results will not be affected by the modification done. Fixed Boundary Constraints are applied to the reduced model at the cutting location. The reduced model helps in fast processing of the LS Dyna runs due to reduced number of elements.
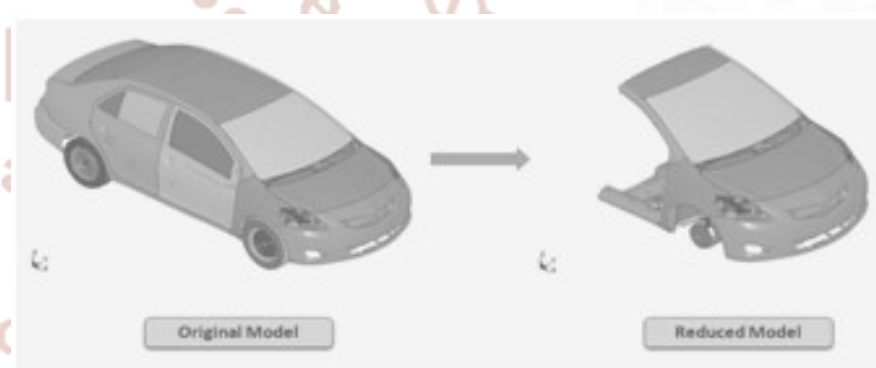

Figure. 5 car model cut for analysis

\section{Test Procedure}

The Reduced Car Model is at the same level when the Full Vehicle is standing on the level floor as it is arrested in software and also the degree of freedom been arrested. All translational and rotational degrees of freedoms are fixed (arrested) at the cutting location of BIW. Head is positioned as per Adult Head Impact Zone at $65^{\circ}$ to horizontal. The head is impacted on different locations as the location has been assigned by the numbers. The Head is impacted with initial velocity of $9.7 \mathrm{~m} / \mathrm{s}$. Head accelerations are measured from the accelerometer which is fitted in Head form.

\section{FE Model Setup\& Boundary Conditions}

Test Set-up consists of the reduced car model and the adult head form. The Reduced car model is fixed at BPillar cut line. Then the calibrated head form is positioned so as to hit the desired location at an angle of $65^{\circ}$ to horizontal. The impact point is selected as per the regulation guideline for Adult Head Impact 
Zone. Figure 6 shows the boundary condition applied on the reduced car model.

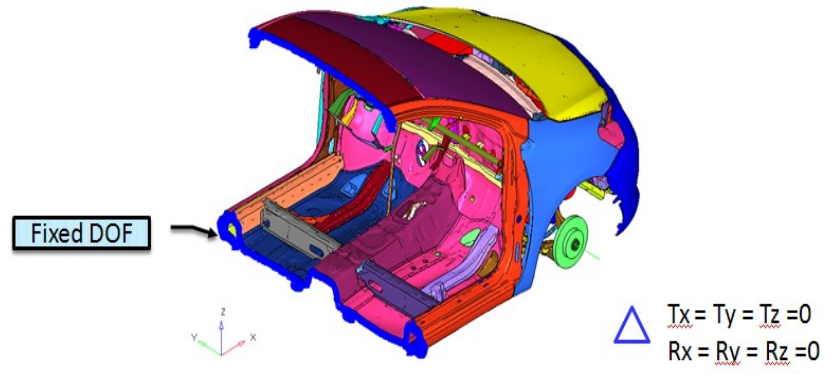

Figure 6 boundary condition applied to reduced model

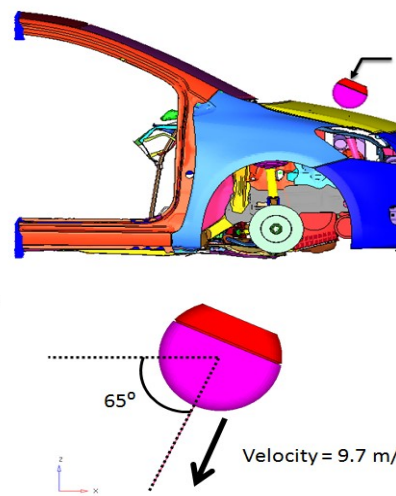

Adult Headform

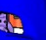

Figure 7 Experiment set up

\section{Baseline Results}

As shown below the points consider for the test are shown with their numbers. The point P0 is the center point of the hood and considered as reference point in this case. The points $\mathrm{P} 1 \mathrm{~A}$ and $\mathrm{P} 1 \mathrm{~B}$ are $165 \mathrm{~mm}$ apart from reference point. The point $\mathrm{P} 2 \mathrm{~A}$ and $\mathrm{P} 2 \mathrm{~B}$ are $165 \mathrm{~mm}$ from $\mathrm{P} 1 \mathrm{~A}$ and $\mathrm{P} 1 \mathrm{~B}$ respectively.

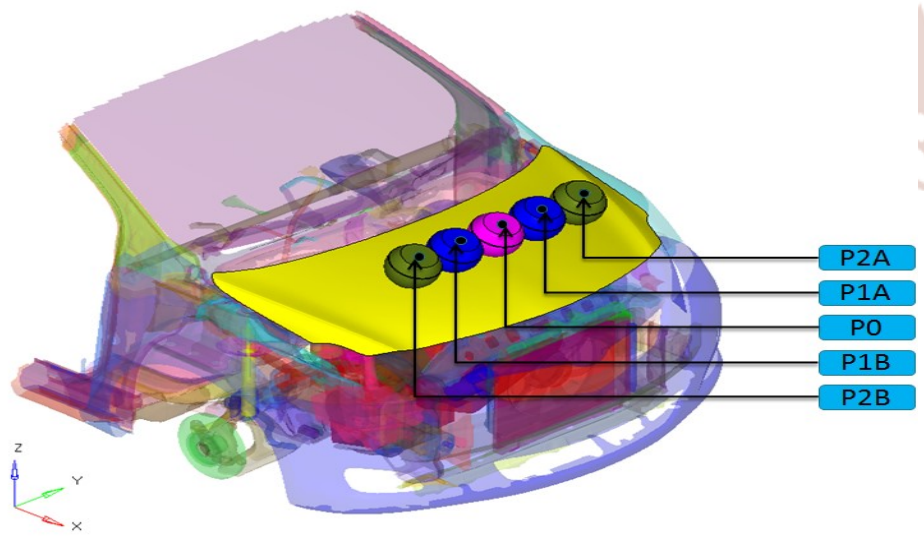

Figure 8 Position of headform impact position on hood

\section{1) Animation instances}

Animation instances for test point P0 is shown in figure 9. The animation shows the impact of head on hood at different time instant. This time fraction is in point second.

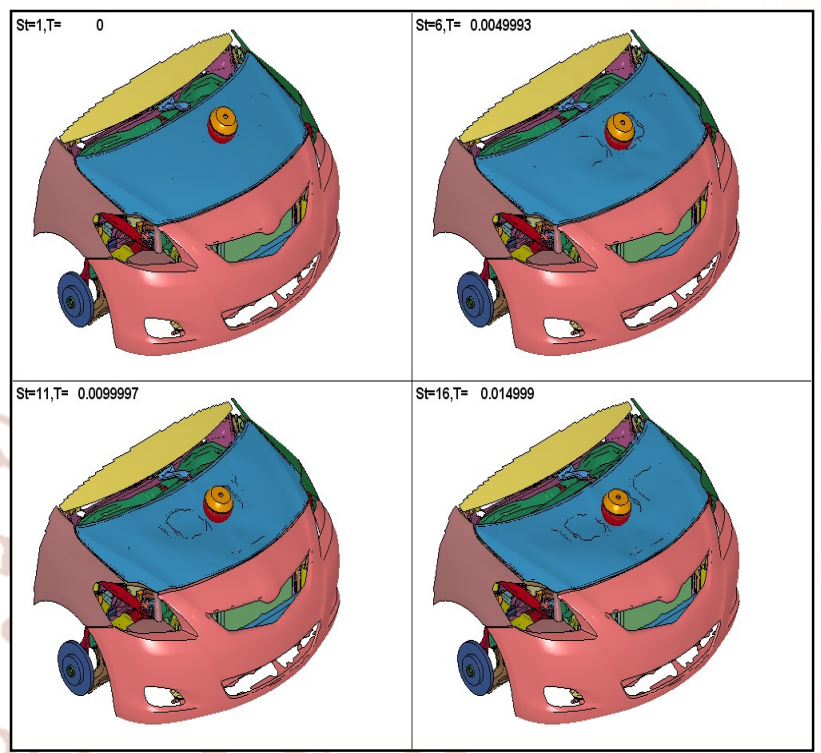

Figure 9 Animation instances for test point P0

\section{2) Overall Stress Plot}

The overall stress plot for point $\mathrm{P} 0$ is distributed along the hinge supports. The maximum stress developed at the head impact section.

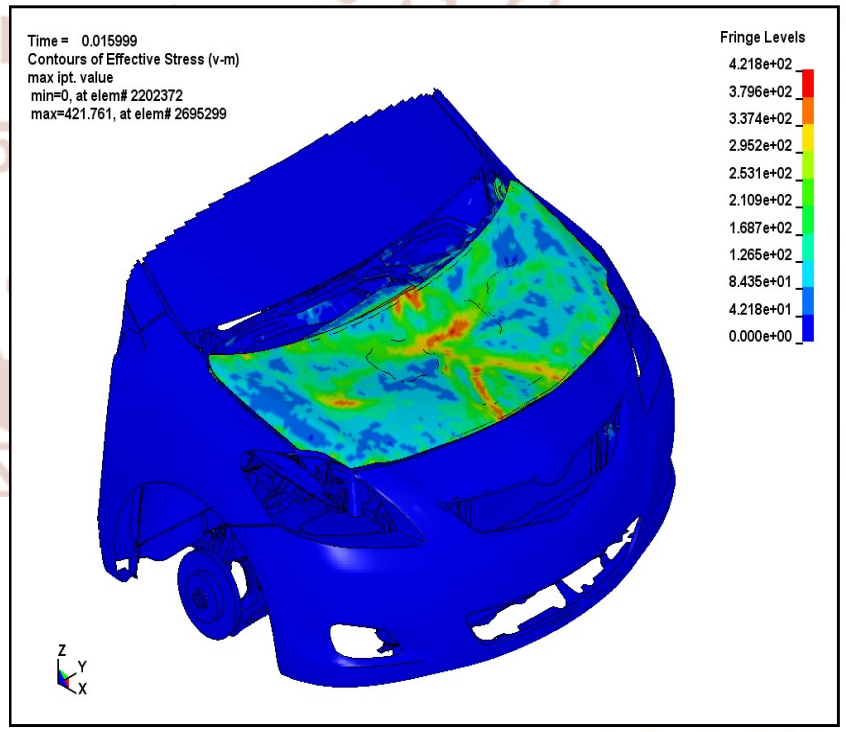

Figure 10 Overall Stress Plot for test point P0

\section{3) Overall Strain Plot}

The overall strain plot for point P0 has maximum value at the impact section. In this plot the fringe levels on hood shows the minimum damage to pedestrian head will be possible when the thickness is optimum. 




Figure 11 Overall Strain Plot for test point P0

and the hood skin thicknesses to protect pedestrians while maximizing the hood stiffness. The method presented in this study uses the regression technique to design constraints for the optimization problem. The proposed algorithm identifies numerous critical positions on the hood surface with respect to pedestrian safety. The algorithm used to optimize the thicknesses is solved by combining LS-DYNA and LS-OPT to simulate and analyze the simulation results.

\section{References}

1) World Health Organization. Global Status Report on Road Safety: Time for Action. Geneva, Switzerland: WHO Press. (2009).

2) Teng T-Land NgoV-L, "Optimization of hood thicknesswith respect to pedestrian safety", DOI: 10.1243/09544070JAUTO1477, CASE STUDY 1513, JAUTO1477, Proc. IMechE Vol. 224 Part D: J. Automobile Engineering, publication on 16 June 2010

\section{4) Head Injury Criteria (HIC)}

The obtained HIC value for point P0 is 159.2, which is the acceptable limit of HIC.

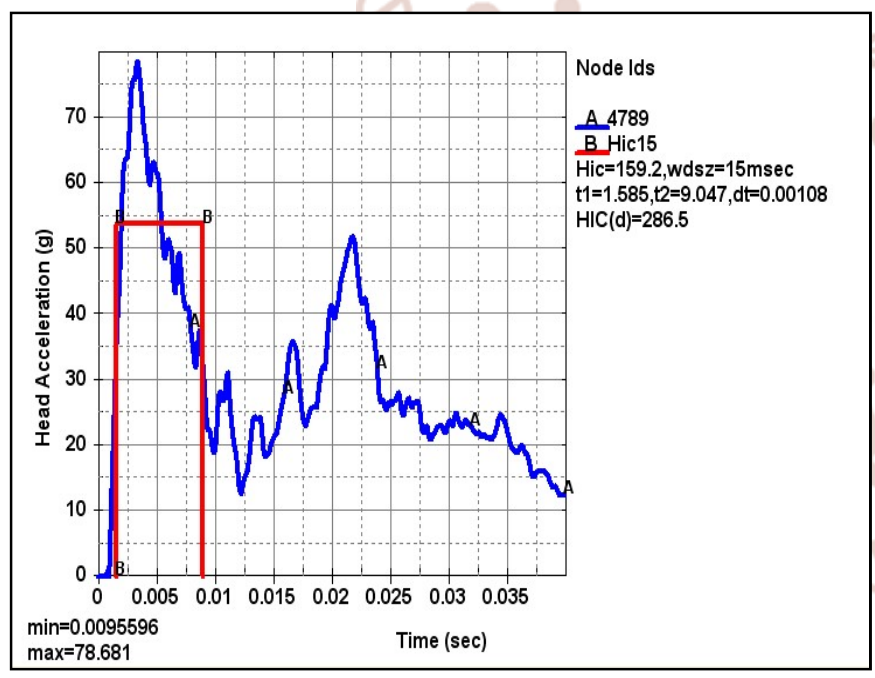

Figure 12. HIC for test point P0

Similarly the simulation for all points is carried out.

\section{Conclusion}

This result shows that the interdependence of the HIC value, the hood reinforcement thickness, and the hood skin thickness is very difficult. This study analyses and proposes a method of identifying the most effective values for the hood reinforcement thickness
3) Lee J.,YoonK., KangY.,ParkG., "Vehicle Hood And Bumper Structure Design to Mitigate Casualties ofPedestrian Accidents", Paper Number 05-0105

4) National Crime Records Bureau Ministry of Home Affairs Government of India East Block - 7, R.K. Puram New Delhi, "Accidental Deaths and Suicides in India 2010"

5) Uniform provisions concerning the approval of motor vehicles with regard to their pedestrian safety performance, Addendum 126: Regulation No. 127, Entry into force: 17 November 2012, 7 January 2013

6) "FHWA/NHTSA National Crash Analysis Center", The George Washington University, Ashburn, Virginia, USA, Applications, Finite element model archive, 2000-2009

7) F. A. Berg, M. Egelhaaf, J. Bakker, H., Burkle, R. Herrmann, and J. Scheerer, "Pedestrian protection in Europe - the potential of car design and impact testing", Report for the United Nations, UN Economic Commission for Europe.

8) "National Center for Statistics and Analysis", Motor vehicle traffic crash fatality counts and estimates of people injured for 2012: 2012 annual assessment. Report DOT HS 811 552, National 
International Journal of Trend in Scientific Research and Development (IJTSRD) ISSN: 2456-6470

Highway Traffic Safety Administration, Washington, DC, USA, February 2012.

9) Y. H. Han, and Y. W. Lee, "Development of a vehicle structure with enhanced pedestrian safety", SAE paper 2003-01-1232, 2003

10) C. K. Simms, "Developments in crash safety: a triumph of design in bioengineering", In Perspectives on design and bioengineering: essays in honour of C. G. Lyons (Eds C. K. Simms and P. J. Prendergast), 2008, pp. 39-55 (Trinity Centre for Bioengineering, Dublin).
11) I.Kalliske, and F.Friesen, "Improvements to pedestrian protection as exemplified on a standardized car", 17th International Technical Conference on The enhanced safety of vehicles (ESV), Amsterdam, The Netherlands, 4-7 June 2001, paper 283, 10 pp. (National Highway Traffic Safety Administration, Washington, DC

12) V. Philomin, R. Duraiswami, and L. Davis, "Pedestrian tracking from a moving vehicle", IEEE Intelligent Vehicles Symposium (IV 2000), Detroit, Michigan, USA, 3-5 October 2000, pp. 350-355 (IEEE, New York).

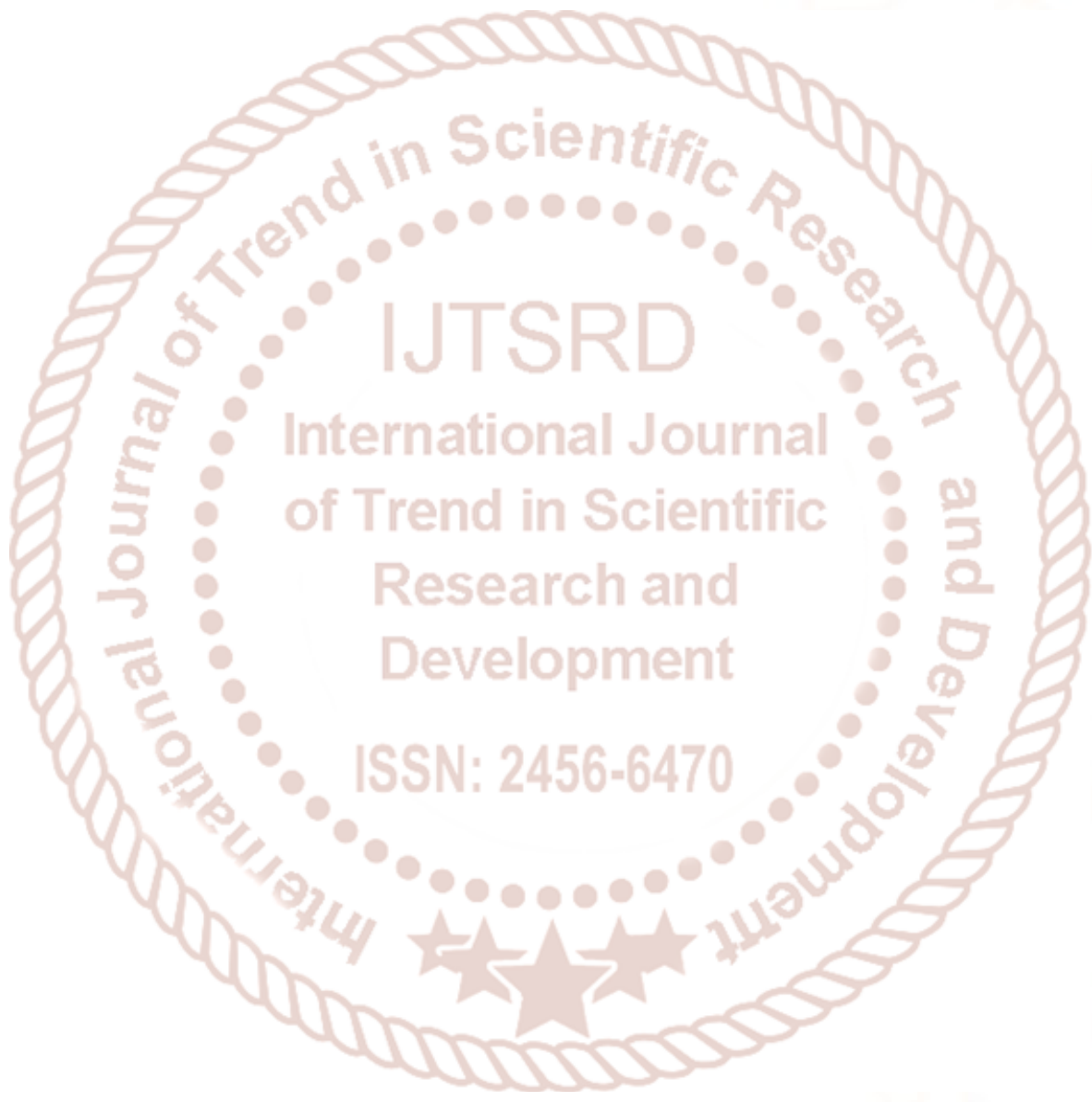

